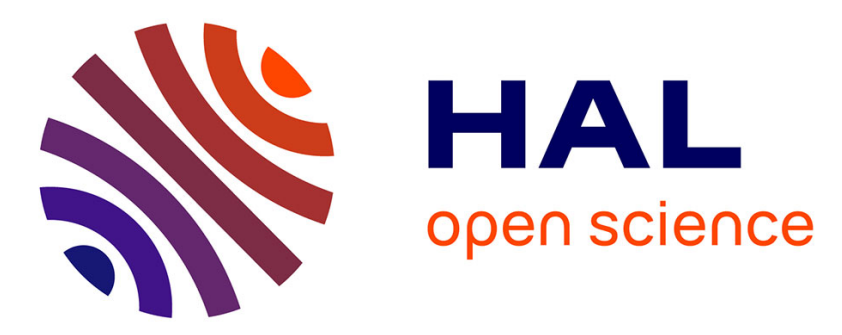

\title{
Emerging polar pollutants in groundwater: Potential impact of urban stormwater infiltration practices
}

Lucie Pinasseau, Laure Wiest, Laurence Volatier, Florian Mermillod-Blondin, Emmanuelle Vulliet

\section{- To cite this version:}

Lucie Pinasseau, Laure Wiest, Laurence Volatier, Florian Mermillod-Blondin, Emmanuelle Vulliet. Emerging polar pollutants in groundwater: Potential impact of urban stormwater infiltration practices. Environmental Pollution, 2020, 266, pp.115387. 10.1016/j.envpol.2020.115387 . hal-02971585

\section{HAL Id: hal-02971585 \\ https://univ-lyon1.hal.science/hal-02971585}

Submitted on 13 Nov 2020

HAL is a multi-disciplinary open access archive for the deposit and dissemination of scientific research documents, whether they are published or not. The documents may come from teaching and research institutions in France or abroad, or from public or private research centers.
L'archive ouverte pluridisciplinaire HAL, est destinée au dépôt et à la diffusion de documents scientifiques de niveau recherche, publiés ou non, émanant des établissements d'enseignement et de recherche français ou étrangers, des laboratoires publics ou privés. 
1 Emerging polar pollutants in groundwater: potential impact of urban stormwater

\section{2 infiltration practices}

3 Lucie Pinasseau ${ }^{\mathrm{a}}$, Laure Wiest $^{\mathrm{a}}$, Laurence Volatier $^{\mathrm{b}}$, Florian Mermillod-Blondin ${ }^{\mathrm{b}}$,

$4 \quad$ Emmanuelle Vulliet $^{\mathrm{a}}$

5

6 a Univ Lyon, CNRS, Université Claude Bernard Lyon 1, Institut des Sciences Analytiques,

$7 \quad$ UMR 5280, 5 Rue de la Doua, F-69100, Villeurbanne, France

8 b Univ Lyon, Université Claude Bernard Lyon 1, CNRS, ENTPE, UMR5023 Laboratoire

9 d'Ecologie des Hydrosystèmes Naturels et Anthropisés (LEHNA), 6 Rue Raphaël Dubois, F-

10 69622, Villeurbanne, France

11

12 *Corresponding author: laure.wiest@isa-lyon.fr

13

14 Declarations of interest: none. 
The quality of groundwater (GW) resources is decreasing partly due to chemical contaminations from a wide range of activities, such as industrial and agricultural enterprises and changes in land-use. In urban areas, one potential major pathway of GW contamination is associated with urban water management practices based on stormwater runoff infiltration systems (SIS). Data on the performance of the upper layer of soil and the unsaturated zone of infiltration basins to limit the contamination of $\mathrm{GW}$ by hydrophilic compounds are lacking. With this aim, the impact of infiltration practices on GW contamination was assessed for 12 pesticides and 4 pharmaceuticals selected according to their ecotoxicological relevance and their likelihood of being present in urban stormwater and GW. For this purpose, 3 campaigns were conducted at 4 SIS during storm events. For each campaign, passive samplers based on the use of Empore ${ }^{\mathrm{TM}}$ disk were deployed in GW wells upstream and downstream of SIS, as well as in the stormwater runoff entering the infiltration basins. Upstream and downstream GW contaminations were compared to evaluate the potential effect of SIS on GW contamination and possible relationships with stormwater runoff composition were examined. Our results showed two interesting opposite trends: (i) carbendazim, diuron, fluopyram, imidacloprid and lamotrigine had concentrations significantly increasing in GW impacted by infiltration, indicating a contribution of SIS to GW contamination, (ii) atrazine, simazine and 2 transformation products exhibited concentrations significantly decreasing with infiltration due to a probable dilution of historic GW contaminants with infiltrated stormwater runoff. The other 7 contaminants showed no general trend. This study demonstrates that passive samplers deployed in GW wells enabled the capture of emerging polar pollutants present at very low concentrations and allowed the assessment of infiltration practices on GW quality. New data on GW and urban stormwater are provided for poorly studied hazardous compounds. 
Capsule: The fate of 16 polar and semi-polar pesticides and pharmaceuticals in groundwater upstream and downstream of stormwater infiltration systems (SIS) was studied.

Keywords: groundwater; passive sampling; pesticides; pharmaceuticals; stormwater infiltration systems; urban stormwater

\section{Introduction}

Groundwater $(\mathrm{GW})$ is the greatest source of freshwater in the world and provides about $75 \%$ of drinking water in the European Union (Danielopol et al., 2004; European Commission, EC, 2006). Aquifers are also vital for industry, agriculture, and groundwater-dependent aquatic ecosystems such as rivers and lakes. However, GW resources are threatened as they are facing a reduction in their quantity and quality due to increased anthropogenic activities. Over the past decade some organic pollutants (e.g. lifestyle and personal care products, industrial chemicals, pesticides, pharmaceuticals and their transformation products (TPs)) have been detected in European GW from ng $\mathrm{L}^{-1}$ to several $\mu \mathrm{g} \mathrm{L}^{-1}$ (Jurado et al., 2012; Lapworth et al., 2012; Loos et al., 2010; Lopez et al., 2015; Postigo and Barceló, 2015; Stuart et al., 2012; Vulliet et al., 2014). From the several sources and pathways of GW contamination (e.g., agricultural practices, industrial contamination of soils, etc), stormwater infiltration practices remain poorly studied whereas they can constitute a potential major pathway for GW contamination. Stormwater infiltration systems (SIS) are etc developed in urban areas to mitigate the risk of flooding and offset reduced GW recharge due to road surfacing. Detention/infiltration basins in urban areas receive stormwater runoff collected from impervious surfaces (roads and car parks), which is then infiltrated through a porous medium (i.e. soil and unsaturated zone) (Marsalek and Chocat, 2002; Mermillod-Blondin et al., 2015; Voisin et al., 2018). However, urban stormwater runoff are often contaminated by 
heavy metals, polycyclic aromatic hydrocarbons and polar emerging pollutants such as pesticides and more specifically biocides from building materials, pharmaceuticals and personal care products (Bollmann et al., 2014; Fairbairn et al., 2018, Gasperi et al., 2014, 2012; Launay et al., 2016, Müller et al., 2020, Paijens et al., 2020, Spahr et al., 2020; Zgheib et al., 2012). Pesticides come from the maintenance of urban green surfaces such as public parks, gardens, children's play areas, roadside verges or riverside footpaths. Pharmaceuticals are more rarely investigated in stormwater runoff but several studies reported stormwater contamination by sewage pollutants in separate sewer systems (Sidhu et al., 2013; Zgheib et al., 2012). Pharmaceuticals in stormwater can also originate from recreational water discharges or outdoor human dejections. Consequently, SIS designed for rapid infiltration of stormwater runoff increase the risks of aquifer contamination. Previous studies demonstrated that the upper layer of soil and the unsaturated zone could act as efficient filters for hydrophobic contaminants (Datry et al., 2004; Tedoldi et al., 2016; Winiarski et al., 2006), with a minor risk of leaching (Nogaro et al., 2007). However, this retention efficiency of the soil and unsaturated zone has not been proven for more hydrophilic compounds such as pesticides and pharmaceuticals that may be present in stormwater runoff. Several studies have already pointed out that SIS are probably responsible for GW contamination by pesticides. By evaluating the influence of detention basins on GW quality, Fischer et al. (2003) showed a higher frequency of atrazine, carbaryl, metolachlor and prometon in wells impacted by detention basins than in wells located outside the influence of detention basins. Marmonier et al. (2013) observed similar results for almost 12 pesticides by comparing GW located in aquifer zones non impacted and aquifer zones impacted by urban stormwater infiltration basins. Likewise, Hensen et al. (2018) measured the transfer of contaminants through a SIS (basin) and showed that stormwater infiltration contaminated GW with 3 biocides applied as preservatives on facades and their TPs. However, it remains several 
knowledge gaps concerning the assessment of GW contamination by emerging organic contaminants associated with SIS. First, the occurrence and fate of some hazardous pollutants such as certain less-studied polar pesticides, in addition to pharmaceuticals, remain poorly studied. Second, the measurement of organic contaminants in GW is challenging as they occur at low (ng $\mathrm{L}^{-1}$ to $\mathrm{pg} \mathrm{L}^{-1}$ ) and variable concentrations. To circumvent this problem, passive sampling approaches have to be deployed to detect contaminants usually found at very low concentrations. Passive sampling also gave a more accurate assessment of groundwater contamination than conventional spot sampling (Brack et al., 2017, Jones et al., 2015, Miège et al., 2015, Mills et al., 2014). Therefore, passive samplers such as Empore ${ }^{\mathrm{TM}}$ disk-based samplers appear as promising tools for the determination of contaminants in the environment as they are easy to use for a wide range of applications (Page et al., 2014, Petrie et al., 2016; Pinasseau et al., 2020; Shaw and Mueller, 2009; Vermeirssen et al., 2013; Vrana et al., 2005). These disks can accumulate analytes on a receiving phase over several days or weeks and the analyte pre-concentration allows for an overall increase of the analytical sensitivity of the procedure. Moreover, changes in average contaminant concentrations over the sampling period are taken into account. Therefore, these devices are very pertinent to assess the occurrence of emerging polar pollutants in GW impacted by urban stormwater infiltration practices that create pulses of stormwater runoff and solutes in GW during rainfall events (Datry et al., 2003). Nevertheless, to the best of our knowledge, their deployment in GW is still rare and only one study has reported their use for monitoring organic contaminants in such kind of infiltration system (Page et al., 2014).

In this context, the present study aimed to assess the effects of urban stormwater runoff infiltration on GW contamination by polar and semi-polar pesticides and pharmaceuticals using Empore ${ }^{\mathrm{TM}}$ disk-based sampler. A list of 16 targeted contaminants was selected according to several criteria: their environmental and ecotoxicological interest, their frequent 
detection at our study sites based on previous studies (Marmonier et al., 2013; Pinasseau et al., 2019, 2020) and their physico-chemical properties. Less-studied hazardous compounds such as bromacil, fluopyram, imidacloprid and lamotrigine were also investigated to supplement these works.

Three campaigns of 10 days were conducted at 4 SIS during storm events in winter. For each SIS, the potential impact of infiltration practices on GW contamination was assessed by comparing masses accumulated on passive samplers of the 16 pesticides and pharmaceuticals in GW non impacted by urban stormwater runoff infiltration (aquifer zone located upstream of SIS) and in GW impacted by urban stormwater runoff infiltration (aquifer zone located downstream of SIS in the plume of infiltrated stormwater). Qualitative characterization of the stormwater runoff entering the infiltration basins was also undertaken for the same 16 contaminants in order to evaluate the potential relationships between stormwater runoff composition of pollutants and GW contamination by stormwater runoff infiltration.

\section{Material and Methods}

\subsection{Studied sites and experimental design}

The experiments were undertaken in 4 SIS located in the eastern metropolitan area of Lyon (France) and monitored in the framework of the field observatory in urban hydrology (OTHU) (further details of the SIS are given in Marmonier et al. (2013), Pinasseau et al. (2019), Voisin et al. (2018). Unsaturated zone thickness, average infiltration time from basin surface to GW, well depth, infiltration surface of the basins, catchment area, and surrounding areas of each SIS are given in Table S1. The 4 SIS (Django Reinhardt (DJR), Chemin de Feyzin (FEY), Grange Blanche (GB) and Campus of the University Lyon 1 (IUT)) collected stormwater runoff from impervious urban areas (mainly roads, car parks and building surface 
materials) although land use (agricultural, commercial, residential and/or industrial activities) varied among areas surrounding sites. All infiltration basins receive exclusively stormwater runoff. Domestic and industrial wastewaters are conveyed in separate sewer systems and do not reach stormwater infiltration systems. A plastic tank was placed at the bottom of each stormwater infiltration basin (dived in soil) for measurements of contaminants on stormwater runoff entering the basin. Each SIS was equipped with two GW wells: a well located outside the area of influence of the stormwater plume induced by infiltration (SIS-up) which was used as a control well, and a well located in the immediate downstream vicinity of the infiltration basin (SIS-dw) used as a recharge well because it intersected the stormwater plume induced by the infiltration of stormwater runoff (Figs. 1 and S1). As performed for microbial GW assessment using artificial substrates (Mermillod-Blondin et al., 2019; Voisin et al., 2020), these wells were used to incubate passive samplers (see below) during 10 days for contaminant assessment of GW by stormwater infiltration (Pinasseau et al., 2019). The wells consisted in either polyvinyl chloride or methacrylate tubes (with a minimum internal diameter of $5.5 \mathrm{~cm})$ perforated at their lower end $(0.5 \mathrm{~m})$ to allow an efficient hydraulic connection with the aquifer. Previous work has shown that at these 4 SIS, the bulk water properties (conductivity, dissolved oxygen, and temperature) measured in the wells was similar to that of the GW in the surrounding aquifer (Foulquier et al., 2010; Voisin et al., 2018).

Three campaigns were undertaken over a period of ten days in the 4 studied SIS: between 8 th - 18th of December, 2017, between 26th of October - 5th of November, 2018 and between 14th -24 th of November, 2019. The three campaigns were performed in winter to obtain 3 replications of the experiment by limiting a potential seasonal effect on the results. During these three seasons, the amounts of precipitation during the 10 days of passive sampler 
incubation were $30.3 \mathrm{~mm}$ in December 2017, $60.9 \mathrm{~mm}$ in November 2018 and $66.1 \mathrm{~mm}$ in

164 November 2019. For each campaign, passive samplers were used to analyze target

165

166

167 contaminants in runoff drained into the basins (surface plastic tanks) and in GW beneath the basins (SIS-up and SIS-dw wells). Passive samplers were based on polystyrene divinylbenzene (SDB-XC) Empore ${ }^{\mathrm{TM}}$ disks (EDs) (47 mm diameter, $12 \mu \mathrm{m}$ particle size, 0.5 mm thick) purchased from 3M (Neuss, Germany). Deployment rigs were designed with the University of Portsmouth (Portsmouth, UK) to fit into GW well dimensions (see details in Pinasseau et al. (2019)). Each rig held 9 individual EDs (only 4 individual EDs for the campaign 2017) to obtain replicated analyses per rig (each ED being analyzed independently). Details of EDs preparation before deployment in the field as well as passive sampler adsorption kinetics are given in Pinasseau et al. (2020). A total of 12 ED rigs were used (one rig per plastic tank and well) and deployed per campaign. As environmental conditions (i.e. water turbidity, water temperature, flow rate) measured in the plastic tanks differ from conditions found in GW, contaminant results from stormwater runoff ED rigs were assessed for qualitative purposes only.

In addition, continuous measurements of dissolved oxygen concentration (HOBO® U26, Onset, USA), specific conductance and temperature (LTC Levelogger® Junior, Solinst, Canada) were monitored in GW during the field deployment periods (mean values for each well, SIS and field campaign are reported on Table S2). Physico-chemical measurements were also done on water samples collected in wells with a submerged pump (PP36 inox, SDEC, Reignac sur-Indre, France) at 3 dates during each ED rig deployment period (day 0, day 5 and day 10) to document $\mathrm{pH}$ values (portable $\mathrm{pH}$-meter HQ20, HACH, Dusseldorf, Germany), ${\mathrm{N}-\mathrm{NO}_{3}}_{3}, \mathrm{~N}-\mathrm{NH}_{4}{ }^{+}$and $\mathrm{P}-\mathrm{PO}_{4}{ }^{3-}$ concentrations in $\mathrm{GW}$ (Table S2).

\subsection{Studied contaminants}


Compounds selected for the study were chosen according to their ecotoxicological relevance and their presence in urban stormwater (biocides from building materials) and GW according to literature (key compounds including key pharmaceuticals and pesticides TPs) (Gasperi et al., 2014, 2012; Jurado et al., 2012; Lapworth et al., 2012; Launay et al., 2016; Loos et al., 2010; Paijens et al., 2020; Postigo and Barceló, 2015; Stuart et al., 2012). Most of them were also frequently detected at our study sites and are presumably indicators of the SIS catchments pollution (Marmonier et al., 2013; Pinasseau et al., 2019, 2020). Their physicochemical properties (polar and semi-polar with probability of reaching GW) was also a selection criterion. To supplement these works, little studied hazardous compounds such as bromacil, fluopyram, imidacloprid and lamotrigine, for which there are still few or no GW data in the literature, were also investigated (Table 1).

\subsection{Sampling and analysis}

After passive sampler deployment and collection, contaminant extraction from EDs were performed according to Pinasseau et al. (2020). Briefly, EDs were extracted using $10 \mathrm{~mL}$ of acetone/methanol $(50 / 50 ; v / v)$. With this extraction protocol, more than $81 \%$ of the compounds had a recovery between $70 \%$ and $120 \%$ (Pinasseau et al., 2020). Then, triplicate extracts were pooled and evaporated to dryness. Finally, samples were reconstituted in 500 $\mu \mathrm{L}$ of water/methanol $(95 / 5 ; v / v)$ and diluted 30 times.

Analysis was performed using an Agilent Series 1200 HPLC system (Agilent Technologies, Massy, France) (binary pump) coupled to a triple quadrupole mass spectrometer (MS) (5500 QTrap, AB Sciex, Les Ulis, France) equipped with an electrospray ion (ESI) source working in positive ionization mode. The chromatographic separation was performed with a Poroshell 120 EC-C 18 column $(2.1 \times 50 \mathrm{~mm}, 2.7 \mu \mathrm{m}$ particle size) (Agilent Technologies). The column 
oven temperature was $30{ }^{\circ} \mathrm{C}$, the injection volume was $20 \mu \mathrm{L}$ and the flow rate was $500 \mu \mathrm{L}$ $\min ^{-1}$. Mobile phase (A) was water and mobile phase (B) was methanol with $0.1 \%$ formic acid in both phases (see Pinasseau et al. (2020) for the gradient elution details). MS detection was performed in the multiple reaction monitoring (MRM) mode (see Pinasseau et al. (2020)). Method detection and quantification limits are reported in Table S3.

\subsection{Statistical analysis}

The influence of SIS on GW contamination was visualized using a principal component analysis (PCA) performed with contents of the 16 contaminants measured after deployment in 8 wells (1 SIS-up well and 1 SIS-dw well per SIS, 4 SIS) for the 3 campaigns $(2017,2018$, 2019). This analysis allowed to compare samples by transforming pollutant contents to a new set of variables, the principal components (PCs), which were uncorrelated, and which were ordered so that the 2 first PCs retain most of the variation present in all of the original variables. Scores of the samples $(24=4$ SIS $* 2$ wells $* 3$ dates $)$ were displayed on a factorial map for comparisons. The variables (pollutants) were represented on a correlation circle indicating the contribution of each variable on PC1 and PC2. Thus, this analysis permitted to determine group of contaminants presenting the same patterns of sample distribution and which contaminants tended to differ between SIS-up and SIS-dw GW extracts. Following this analysis, contents of specific contaminants were compared between SIS-up and SIS-dw wells of each site using repeated-measures ANOVAs (RM-ANOVAs) with site as fixed factor and recharge as repeated factor to take into account the non-independence of SIS-up and SIS-dw wells in each site for each campaign (the 3 campaigns acted as replicates). The Mauchly's sphericity test, the Shapiro-Wilk's test, and the Levene's test, were used to verify the statistical assumptions of sphericity, normality, and homoscedasticity, respectively. When 
these assumptions were not proved, the variables (contaminant content) were $\log (\mathrm{x}+1)$ transformed before RM-ANOVA tests. Statistical analyses were carried out using R version 3.2.3 software (R Development Core Team, 2015). Significance for statistical tests (RMANOVA) was accepted for a first species risk set at $\alpha<0.05$.

\section{Results and discussion}

\subsection{Stormwater runoff characterization}

After each campaign, the deployment rigs placed in the plastic tanks were retrieved and the stormwater runoff extracts were analyzed qualitatively. For each site, results were displayed in a Venn diagram showing the percentage of contaminants that were detected during one, two or three campaigns (Fig. 2). At least, 12 out of the 16 selected contaminants were found in the stormwater runoff extracts of each site by considering all campaigns. Carbendazim, DEET, diclofenac and diuron were detected in all extracts and 50, 54, 62 and $71 \%$ of the contaminants were recovered from passive samplers during the 3 campaigns for IUT, FEY, GB and DJR, respectively. In addition, there were only few cases (4.3\% in the dataset) where a contaminant was only present in one of the 3 campaigns. This means that the contaminant compositions of stormwater runoff entering each infiltration basin were comparable among the 3 campaigns, suggesting no drastic change in contaminant sources from 2017 to 2019 during winter. Moreover, the contaminants detected in urban stormwater runoff of the 4 SIS were classically observed in urban drainage systems (Fairbairn et al., 2018; Spahr et al., 2020). 
260 For each campaign, contaminant masses accumulated on disks (Table S3) were used to evaluate the impact of SIS on GW contamination by comparing results obtained from nonimpacted SIS-up well and SIS-dw well for each SIS. This influence of SIS on GW contaminants was visualized using a PCA (Fig. 3). The PC1 and PC2 axes of the PCA explained $57 \%$ of the variability contained in the data matrix, with $32 \%$ on the first axis (Fig. 3a). The correlation circle (Fig. 3b) indicated that groups of contaminants having the same distributions among samples. For example, the three pesticides DEA, simazine and atrazine presented the same distribution among samples with the highest concentrations obtained for samples having a negative score on PC1 and a positive score on PC2 like the sample performed in SIS-up well of Django-Reinhardt in 2017 (left bottom panel in Fig. 3c). To evaluate the impact of stormwater runoff infiltration on GW quality, we observed that extracts obtained from SIS-dw wells tended to have lower scores along axis PC2 than extracts from SIS-up wells for the 4 sites and the 3 campaigns (Fig. 3c). This partitioning was associated with two opposite trends when comparing extracts from SIS-up wells with extracts from SIS-down wells: a decrease in the contents of atrazine, BAM, DEA and simazine and an increase in the contents of carbendazim, diuron, fluopyram, imidacloprid and lamotrigine, and sulfamethoxazole only for FEY site (Fig. 3b). For FEY site, SIS-dw GW extracts also presented lower scores than SIS-up GW extracts along axis PC1, indicating an increase in carbamazepine and hexazinone in SIS-dw GW for the 3 campaigns. For the other 3 sites, we did not observe clear trends along PC1 axis, except for the campaign of 2017 in the SIS-up GW of DJR site characterized by high contents of atrazine, DEA and simazine. 
This PCA analysis allowed to classify the 16 contaminants into 3 main groups depending on their distributions: contaminants with concentrations increasing with infiltration, suggesting a contribution of the SIS on GW contamination (carbendazim, diuron, fluopyram, imidacloprid and lamotrigine), contaminants with concentrations decreasing with infiltration, suggesting a dilution of GW contamination by SIS (atrazine, BAM, DEA and simazine), and contaminants which were apparently not influenced by infiltration in all sites or whose influence differed among sites (bromacil, carbamazepine, DEET, diclofenac, hexazinone, metolachlor and sulfamethoxazole).

\subsection{Contaminants with concentrations increasing with stormwater infiltration}

For imidacloprid, carbendazim, lamotrigine, diuron and fluopyram, concentrations measured in SIS-dw GW were significantly higher than those measured in SIS-up GW (Fig. 4a, RMANOVAs, "SIS-up GW versus SIS-dw GW" effet, $F_{(1,8)}>19, \mathrm{p}<0.01$ for the 5 contaminants), indicating a contribution of SIS to GW pollution by these contaminants. This conclusion was confirmed by the detection of these 5 compounds in runoff collected from the 4 SIS (for at least 2 or 3 dates), at the exception of imidacloprid which was not detected in runoff from IUT site (Fig. 2). Diuron was quantified in $96 \%$ of GW extracts, with a maximum concentration reaching $34.8 \mathrm{ng} \mathrm{disk}^{-1}$ (Fig. 4a, Table S3). First used in 1951, it is still authorized in some products for the protection of building materials, despite being banned for agricultural uses since 2003 (Table 1). These diuron usages could explain its occurrence in urban runoff (drainage of built areas) and its impact on GW quality because the aquifer was less contaminated by agricultural practices occurring upstream in its catchment area. Our results also confirmed previous observations reporting the presence of diuron in all environmental compartments and in GW due to its wide spreading and persistence in the 
environment (Cabeza et al., 2012; Hensen et al., 2018; Lapworth et al., 2015; Loos et al., 2010; Reh et al., 2013). In comparison with diuron, imidacloprid, carbendazim, lamotrigine and fluopyram exhibited very low concentrations or, in most cases, no detection at all in SISup GW located outside the influence of stormwater infiltration. This observation suggests that stormwater infiltration was almost exclusively responsible for the presence of these contaminants in SIS-dw GW. These 4 contaminants are in use today (Table 1). Carbendazim, found in $96 \%$ of GW extracts with a maximum concentration of 4.2 ng disk $^{-1}$ (Fig. 4a, Table S3), has been banned for agricultural uses since 2009 but is still authorized in some products for the protection of building materials. It has been already detected in European GW by Hernández et al. (2008), Reemtsma et al. (2013) and Vulliet et al. (2014). Lamotrigine and fluopyram, quantified in 79 and $67 \%$ of GW extracts with maximum concentrations of 11.3 and $1.4 \mathrm{ng} \mathrm{disk}^{-1}$, respectively (Fig. 4a, Table S3), are the most recent contaminants among the 16 investigated. They were used for the first time in the 2000s (Table 1). It could explain the lack of study reporting the presence of fluopyram in GW and the presence in literature of only one study reporting lamotrigine (Bollmann et al., 2016). Despite its introduction in 1990s, imidacloprid, an insecticide detected in $71 \%$ of GW extracts with a maximum concentration of $5.6 \mathrm{ng} \mathrm{disk}{ }^{-1}$ (Fig. 4a, Table S3), has been poorly investigated in European GW and, consequently, only one study in literature reported the occurrence of this compound in GW (Hernández et al., 2008).

In the present study, imidacloprid presented singular results: its concentration was higher in SIS-dw GW than in SIS-up GW of IUT site (see campaign 2017 on Fig. 4a) despite its absence in stormwater runoff of IUT site (Fig. 2). This SIS-associated contamination of GW with a compound which was not detected in stormwater runoff might have been due to the leaching of this compound from soil and sediment particles on which it has been previously 
trapped and accumulated during several years of infiltration basin operation. This adsorptiondesorption mechanism has been already observed with carbendazim which can be temporarily trapped on soil and thereafter partly remobilized in water (Sébastian et al., 2015). As described by Hensen et al. (2018), each stormwater infiltration event could have led to the leaching of some contaminants absorbed in the soil and/or the unsaturated zone. However, the role of the infiltration medium to trap hydrophilic compounds is still unclear, even if the soil and the unsaturated zone have the potential to efficiently retain some hydrophobic contaminants like hydrocarbons or heavy metals (Datry et al., 2004; Tedoldi et al., 2016; Winiarski et al., 2006). Thus, more research is needed to confirm the hypothesis that adsorption-desorption mechanisms could explain the GW enrichment in imidacloprid by SIS.

\subsection{Contaminants with concentrations decreasing with stormwater infiltration}

For DEA, simazine, BAM, and atrazine, concentrations observed in SIS-dw GW were significantly lower than those observed in SIS-up GW (Fig. 4b, RM-ANOVAs, "SIS-up GW versus SIS-dw GW" effet, $F_{(1,8)}>8.5, \mathrm{p}<0.05$ for the 4 contaminants), indicating that stormwater runoff infiltration reduced the concentrations of these 4 contaminants in GW. Although these compounds were detected in stormwater runoff (Fig. 2), they were probably present at lower concentrations in stormwater runoff than in SIS-up GW because infiltrated stormwater probably reduced their concentrations in SIS-dw GW by dilution. Such interpretation assumes that DEA, simazine, BAM, and atrazine were mainly found in GW and this was probably the case. Indeed, DEA, simazine, BAM and atrazine were detected in $100,96,88$ and $100 \%$ of GW extracts with maximum concentrations of 46.9, 29.3, 13.1 and $87.9 \mathrm{ng} \mathrm{disk}^{-1}$, respectively (Fig. 4b, Table S3). In comparison, DEA, simazine, BAM and atrazine were detected only in 58,58, 41 and $66 \%$ of runoff extracts, respectively (Fig. 2). 
This widespread occurrence of atrazine, BAM, DEA and simazine in GW have been largely reported in literature (Lapworth et al., 2015). Atrazine and simazine have been banned since 2003 but, like DEA, they have already reached GW for many years (Bono-Blay et al., 2012; Kuster et al., 2010; Lapworth et al., 2015; Loos et al., 2010; Lopez et al., 2015). BAM, a common degradation product of dichlobenil (herbicide banned in 2009) and fluopicolide (fungicide still authorized), has been also frequently detected in European GW (Lapworth et al., 2015; Lopez et al., 2015; Postigo and Barceló, 2015). Although some of these contaminants have been banned, the renewal time of aquifers, which includes the transfer time in the unsaturated zone, may take years to decades and could therefore explain the persistence of these contaminants in GW (Chen et al., 2019a; Gleeson et al., 2012; Gutierrez and Baran, 2009; Swartjes and Van der Aa, 2019; Wang et al., 2016). Moreover, it has been reported that pesticide degradation within GW aquifers was low (Baran et al., 2007). Under these conditions, even if a nil or negligible part of the contamination was provided by soil leaching (explaining the occurrence of atrazine or simazine in stormwater runoff), stormwater runoff infiltration reduced the concentrations of these contaminants in $\mathrm{GW}$ by dilution of contaminated GW (SIS-up GW) with less contaminated stormwater runoff.

\subsection{Contaminants not consistently influenced by stormwater infiltration}

No significant influence of stormwater runoff infiltration was observed on concentrations of bromacil, carbamazepine, DEET, diclofenac, hexazinone, metolachlor and sulfamethoxazole over the 4 SIS and 3 campaigns (Fig. 5, RM-ANOVAs, "SIS-up GW versus SIS-dw GW" effet, $F_{(1,8)}<2.1, \mathrm{p}>0.15$ for the 7 contaminants). As observed for atrazine or simazine, we could expect a dilution effect in GW for bromacil and hexazinone because (1) these compounds have been banned in 2001 and 2007 respectively (Table 1), (2) they were not 
detected in stormwater runoff (Fig. 2) and (3) they were present in GW (63 and 83\% of GW extracts with maximum concentrations of 8.9 and $9.1 \mathrm{ng} \mathrm{disk}^{-1}$ for bromacil and hexazinone, respectively, Fig. 5, Table S3). However, the opposite results were observed on these compounds in FEY and DJR sites with higher concentrations obtained in SIS-dw GW than in SIS-up GW (Fig. 5). As these results cannot be exclusively explained by the compositions of infiltrated stormwater runoff and SISs-up GW, it can be assumed that two mechanisms (desorption and dilution) are involved in the fate of these contaminants in SIS: each stormwater runoff infiltration event would both leach these compounds from the soil and unsaturated zone, and dilute those already present in the GW in variable proportions depending on SIS. The same mechanisms probably occurred for the 5 other contaminants which did not exhibit consistent changes in concentration with stormwater infiltration. Indeed, stormwater infiltration at FEY site significantly contributed to GW deterioration by sulfamethoxazole and carbamazepine, while these same compounds appear to be diluted at GB site (Fig. 5). In the same way, stormwater infiltration at FEY site tended to increase sulfamethoxazole and carbamazepine concentrations in GW whereas no trend was observed for the same site for diclofenac, DEET and metolachlor concentrations (Fig. 5).

The lack of clear stormwater infiltration effect on bromacil, carbamazepine, DEET, diclofenac, hexazinone, metolachlor and sulfamethoxazole concentrations among sites could be also due to the background contamination in the environment and GW that reduced our ability to detect changes associated with SIS. Indeed, carbamazepine, an antiepileptic known to be persistent and frequently detected in GW (Loos et al., 2010; Stuart et al., 2014; Vulliet et al., 2014; Vulliet and Cren-Olivé, 2011),was detected in 100\% of GW extracts with a maximum concentration of $47.7 \mathrm{ng} \operatorname{disk}^{-1}$ (Fig. 5, Table S3). Sulfamethoxazole and diclofenac, pharmaceuticals used in human and veterinary medicine and commonly found in 
Vulliet and Cren-Olivé, 2011), were also quantified in 88 and 58\% of GW extracts with maximum concentrations of 4.2 and $0.8 \mathrm{ng} \mathrm{disk}^{-1}$, respectively (Fig. 5, Table S3). DEET, a domestic insect repellent widely used across the world (Lapworth et al., 2015; Loos et al., 2010; Marques dos Santos et al., 2019; Sorensen et al., 2015) was also found in 100\% of GW extracts with a maximum concentration of $7.1 \mathrm{ng} \mathrm{disk}^{-1}$ (Fig. 5, Table S3). Metolachlor, detected in $100 \%$ of $\mathrm{GW}$ extracts with a maximum concentration of $16.6 \mathrm{ng}^{\text {disk }}{ }^{-1}$ (Fig. 5, Table S3) is also ubiquitous in European GW under its both racemic mixture form (forbidden in 2003) and S enantiomer form (Hildebrandt et al., 2008; Kuster et al., 2010; Loos et al., 2010; Lopez et al., 2015).

To better understand the mechanisms involved in the dynamics of these 7 contaminants, we searched for potential relationships between our contaminant results, the SIS design (Table S1) and the targeted compounds chemical properties (Table 1). Neither the average transit time of stormwater from the basin to GW nor the physico-chemical properties of compounds (i.e. $\mathrm{pKa}, \log \mathrm{D}_{\mathrm{ow}}, \mathrm{GUS}$ index) can be directly related to the significance of SIS-dw GW contamination, as previously concluded by Baran et al. (2007) and Manamsa et al. (2016). For example, contamination of GW by infiltration practice (SIS-up GW versus SIS-dw GW) was the highest for FEY site (Figs. 3, 4 and 5) whereas the unsaturated zone of this site would be the most efficient to retain contaminants as the average transit time of stormwater from surface to GW was more than 2-fold higher in this site $(211.8 \pm 90.5 \mathrm{~h})$ than in other sites (< $86.0 \pm 12.4 \mathrm{~h}$, Table S1). The results mean that some additional parameters and mechanisms are involved in the fate of contaminants in SIS during a stormwater runoff infiltration event: soil composition and physico-chemical properties (Regnery et al., 2017), the presence of preferential pathways and/or retention of compounds due to capillary tension (Wang et al., 2016), and the contaminant degradation by microbial communities (Pitt et al., 1999). 
429 Concerning soil composition, the high concentrations of organic matter (more than $10 \%$ of organic carbon per soil dry mass, (Pigneret et al., 2016)) found in soil of infiltration basins may play a key role on contaminant dynamics. Indeed, organic matter is likely to sorb neutral or non-ionizable compounds, whereas ionizable ones, such as pharmaceuticals, can form electrostatic interactions with clay minerals (Gutierrez and Baran, 2009; Kodešová et al., 2015; Regnery et al., 2017; Valhondo et al., 2018). Moreover, sorption processes can be complicated due to natural heterogeneity, competition for sorption sites and preferential pathways through fractures (Baran et al., 2007; Chen et al., 2019b), and are most certainly reversible (Greskowiak et al., 2017). Consequently, it can be hypothesized that the transport of some contaminants to GW was delayed and/or progressive over several years and that each stormwater runoff infiltration event produced the release of trapped contaminants (Baran et al., 2007; Swartjes and Van der Aa, 2019).

It is worth noting that the choices of targeted contaminants together with the sampling campaign periods and the period of GW quality assessment had major influences on our results. Associated with seasons and meteorological conditions, dry periods followed by intense rainfall events are known to have direct impacts on the number of contaminants and their concentrations in stormwater runoff (Bollmann et al., 2014; Burkhardt et al., 2011; Hensen et al., 2018; Paijens et al., 2020). Indeed, urban pollutants such as herbicides are more likely washed off from building materials and green areas after a long dry period (Burkhardt et al., 2011; Spahr et al., 2020). For pharmaceuticals, it has been reported that they are more transported by stormwater discharge overflow during high volume rainfall events than during low volume rainfall events (Launay et al., 2016; Spahr et al., 2020). Beside seasonal effects that have not been addressed in the present study, another limitation of our work concerns the environmental variability that could have affect passive sampler efficiency. Although the potential value of passive sampling has already been proven for 
monitoring emerging pollutants in water (Brack et al., 2017, Jones et al., 2015, Miège et al., 2015, Mills et al., 2014), the uptake mechanisms of polar compounds on EDs are still not fully understood (Vrana et al., 2016). Environmental variabilities (flow rate, water temperature, turbidity, etc) can affect uptake mechanisms and contribute to variability of water concentration estimates when calibration data are applied (Lissalde et al., 2016). Therefore, using ng disk ${ }^{-1}$ values instead of $n g \mathrm{~L}^{-1}$ values helps to improve the reliability of the results, as we did in this study. Working on three autumn/winter rainfall events enabled us to obtain experimental replications under comparable climatic conditions but, in future investigations, it would be necessary to undertake additional sampling campaigns during spring/summer in order to evaluate how seasonal effects (climatic conditions, contaminant composition of stormwater runoff) influence the role of SIS on GW quality.

\section{Conclusions}

This study was the first to assess the effects of urban stormwater runoff infiltration on GW contamination by 16 polar and semi-polar pesticides and pharmaceuticals using Empore ${ }^{\mathrm{TM}}$ disk-based sampler. To our knowledge, it was the first time that such passive samplers were deployed in GW wells to monitor the infiltration of emerging polar pollutants. This work demonstrates that they enable the capture of contaminants at traces level efficiently. Moreover, new data on GW are provided for recent and/or understudied hazardous contaminants like bromacil, fluopyram, imidacloprid and lamotrigine.

Obtained results highlighted two interesting opposite trends depending on studied contaminants: 5 contaminants (carbendazim, diuron, fluopyram, imidacloprid and lamotrigine) had concentrations significantly increasing with stormwater runoff infiltration, indicating a contribution of infiltration to groundwater contamination, and 4 contaminants 
478 (atrazine, BAM, DEA and simazine) exhibited concentrations significantly decreasing with 479 infiltration due to a probable dilution with stormwater runoff of historic GW contaminants such as atrazine. The fact that the remaining 7 contaminants showed no general trend with site-dependent infiltration effect on their concentrations might be due to: (i) the differences among SIS in historical contaminations of all environmental compartments (urban watershed, soil, unsaturated zone and GW) and (ii) the differences among SIS in soil properties, hydrological transport and microbial processes that would be responsible for the variability observed in contaminant dynamics among SIS.

In further studies, it will be therefore necessary to quantify the processes occurring in the soil and unsaturated zone (sorption and desorption processes, microbial degradation of contaminants) of each SIS. Use of proxy for soil/sediment characteristics (organic matter content, clay percentage), hydrogeological functioning (precise measurements of infiltration rates in each infiltration basin) and microbial activity would help to decrypt the main variables influencing contaminant dynamics during their transfer from infiltration basin to GW. As discussed above, monitoring several rainfall events at different seasons would be necessary to take into account the inter-event variability and the seasonal effects on contaminant transfers. Finally, measurements performed during more than 10 years could be also very promising to evaluate the long time-lag between the use of some contaminants, their dynamics in environmental compartments and the resulting changes on GW quality.

\section{Acknowledgements}

This work was supported by ANR FROG-ANR-16-CE32-0006 project. The authors thank 


\section{References}

Baran, N., Mouvet, C., Négrel, Ph., 2007. Hydrodynamic and geochemical constraints on pesticide concentrations in the groundwater of an agricultural catchment (Brévilles, France). Environ. Pollut. 148, 729-738.

Berlioz-Barbier, A., Vauchez, A., Wiest, L., Baudot, R., Vulliet, E., Cren-Olivé, C., 2014. Multi-residue analysis of emerging pollutants in sediment using QuEChERS-based extraction followed by LC-MS/MS analysis. Anal. Bioanal. Chem. 406, 1259-1266.

Bollmann, A.F., Seitz, W., Prasse, C., Lucke, T., Schulz, W., Ternes, T., 2016. Occurrence and fate of amisulpride, sulpiride, and lamotrigine in municipal wastewater treatment plants with biological treatment and ozonation. J. Hazard. Mater. 320, 204-215.

Bollmann, U.E., Vollertsen, J., Carmeliet, J., Bester, K., 2014. Dynamics of biocide emissions from buildings in a suburban stormwater catchment - Concentrations, mass loads and emission processes. Water Res. 56, 66-76.

Bono-Blay, F., Guart, A., de la Fuente, B., Pedemonte, M., Pastor, M.C., Borrell, A., Lacorte, S., 2012. Survey of phthalates, alkylphenols, bisphenol $A$ and herbicides in Spanish source waters intended for bottling. Environ. Sci. Pollut. Res. 19, 3339-3349.

Brack, W., Dulio, V., Ågerstrand, M., Allan, I., Altenburger, R., Brinkmann, M., Bunke, D., Burgess, R.M., Cousins, I., Escher, B.I., Hernández, F.J., Hewitt, L.M., Hilscherová, K., Hollender, J., Hollert, H., Kase, R., Klauer, B., Lindim, C., Herráez, D.L., Miège, C., Munthe, J., O’Toole, S., Posthuma, L., Rüdel, H., Schäfer, R.B., Sengl, M., Smedes, F., van de Meent, D., van den Brink, P.J., van Gils, J., van Wezel, A.P., Vethaak, A.D., Vermeirssen, E., von der Ohe, P.C., Vrana, B., 2017. Towards the review of the European Union Water Framework Directive: Recommendations for more efficient assessment and management of chemical contamination in European surface water resources. Science of The Total Environment 576, 720-737. https://doi.org/10.1016/j.scitotenv.2016.10.104

Burkhardt, M., Junghans, M., Zuleeg, S., Schoknecht, U., Lamani, X., Bester, K., Vonbank, R., Simmler, H., Boller, M., 2009. Biocides in building fac, ades e ecotoxicological effects, leaching and environmental risk assessment for surface waters (Biozide in Geba"udefassaden e o" kotoxikologische Effekte, Auswaschung und Belastungsabscha"tzung fu" $r$ Gewa" sser). Umweltwissenschaften Schadst. 21 (1), 36e47.

Cabeza, Y., Candela, L., Ronen, D., Teijon, G., 2012. Monitoring the occurrence of emerging contaminants in treated wastewater and groundwater between 2008 and 2010. The Baix Llobregat (Barcelona, Spain). J. Hazard. Mater. 239-240, 32-39.

Chen, N., Valdes, D., Marlin, C., Blanchoud, H., Guerin, R., Rouelle, M., Ribstein, P., 2019a. Water, nitrate and atrazine transfer through the unsaturated zone of the Chalk aquifer in northern France. Sci. Total Environ. 652, 927-938. 
Chen, N., Valdes, D., Marlin, C., Ribstein, P., Alliot, F., Aubry, E., Blanchoud, H., 2019b. Transfer and degradation of the common pesticide atrazine through the unsaturated zone of the Chalk aquifer (Northern France). Environ. Pollut. 255, 113125.

Danielopol, D.L., Gibert, J., Griebler, C., Gunatilaka, A., Hahn, H.J., Messana, G., Notenboom, J., Sket, B., 2004. Incorporating ecological perspectives in European groundwater management policy. Environ. Conserv. 31, 185-189.

Datry, T., Malard, F., Gibert, J., 2004. Dynamics of solutes and dissolved oxygen in shallow urban groundwater below a stormwater infiltration basin. Sci. Total Environ. 329, 215-229.

Datry, T., Malard, F., Vitry, L., Hervant, F., Gibert, J., 2003. Solute dynamics in the bed sediments of a stormwater infiltration basin. J. Hydrol. 273, 217-233.

European Commission. Directive 2006/118/EC of the European Parliament and of the Council of 12 December 2006 on the protection of groundwater against pollution and deterioration. Official Journal of the European Union, 2006.

Fairbairn, D.J., Elliott, S.M., Kiesling, R.L., Schoenfuss, H.L., Ferrey, M.L., Westerhoff, B.M., 2018. Contaminants of emerging concern in urban stormwater: Spatiotemporal patterns and removal by iron-enhanced sand filters (IESFs). Water Res. 145, 332-345.

Fischer, D., Charles, E.G., Baehr, A.L., 2003. Effects of Stormwater Infiltration on Quality of Groundwater Beneath Retention and Detention Basins. J. Environ. Eng. 129, 464-471.

Foulquier, A., Malard, F., Mermillod-Blondin, F., Datry, T., Simon, L., Montuelle, B., Gibert, J., 2010. Vertical change in dissolved organic carbon and oxygen at the water table region of an aquifer recharged with stormwater: biological uptake or mixing? Biogeochemistry 99, 31-47.

Gasperi, J., Sebastian, C., Ruban, V., Delamain, M., Percot, S., Wiest, L., Mirande, C., Caupos, E., Demare, D., Kessoo, M.D.K., Saad, M., Schwartz, J.J., Dubois, P., Fratta, C., Wolff, H., Moilleron, R., Chebbo, G., Cren, C., Millet, M., Barraud, S., Gromaire, M.C., 2014. Micropollutants in urban stormwater: occurrence, concentrations, and atmospheric contributions for a wide range of contaminants in three French catchments. Environ. Sci. Pollut. Res. 21, 5267-5281.

Gasperi, J., Zgheib, S., Cladière, M., Rocher, V., Moilleron, R., Chebbo, G., 2012. Priority pollutants in urban stormwater: Part 2 - Case of combined sewers. Water Res. 46, 6693-6703.

Gleeson, T., Wada, Y., Bierkens, M.F.P., van Beek, L.P.H., 2012. Water balance of global aquifers revealed by groundwater footprint. Nature 488, 197-200.

Greskowiak, J., Hamann, E., Burke, V., Massmann, G., 2017. The uncertainty of biodegradation rate constants of emerging organic compounds in soil and groundwater - A compilation of literature values for 82 substances. Water Res. 126, 122-133.

Gutierrez, A., Baran, N., 2009. Long-term transfer of diffuse pollution at catchment scale: Respective roles of soil, and the unsaturated and saturated zones (Brévilles, France). J. Hydrol. 369, 381-391.

Hensen, B., Lange, J., Jackisch, N., Zieger, F., Olsson, O., Kümmerer, K., 2018. Entry of biocides and their transformation products into groundwater via urban stormwater infiltration systems. Water Res. 144, 413-423.

Hernández, F., Marín, J.M., Pozo, Ó.J., Sancho, J.V., López, F.J., Morell, I., 2008. Pesticide residues and transformation products in groundwater from a Spanish agricultural region on the Mediterranean Coast. Int. J. Environ. Anal. Chem. 88, 409-424.

Hildebrandt, A., Guillamón, M., Lacorte, S., Tauler, R., Barceló, D., 2008. Impact of pesticides used in agriculture and vineyards to surface and groundwater quality (North Spain). Water Res. 42, 3315-3326.

Jones, L., Ronan, J., McHugh, B., McGovern, E., Regan, F., 2015. Emerging priority substances in the aquatic environment: a role for passive sampling in supporting WFD monitoring and compliance. Anal. Methods 7, 7976-7984. https://doi.org/10.1039/C5AY01059D 
Jurado, A., Vàzquez-Suñé, E., Carrera, J., López de Alda, M., Pujades, E., Barceló, D., 2012. Emerging organic contaminants in groundwater in Spain: A review of sources, recent occurrence and fate in a European context. Sci. Total Environ. 440, 82-94.

Köck-Schulmeyer, M., Ginebreda, A., Postigo, C., Garrido, T., Fraile, J., López de Alda, M., Barceló, D., 2014. Four-year advanced monitoring program of polar pesticides in groundwater of Catalonia (NE-Spain). Sci. Total Environ. 470-471, 1087-1098.

Kodešová, R., Grabic, R., Kočárek, M., Klement, A., Golovko, O., Fér, M., Nikodem, A., Jakšík, O., 2015. Pharmaceuticals' sorptions relative to properties of thirteen different soils. Sci. Total Environ. 511, 435-443.

Kuster, M., Díaz-Cruz, S., Rosell, M., López de Alda, M., Barceló, D., 2010. Fate of selected pesticides, estrogens, progestogens and volatile organic compounds during artificial aquifer recharge using surface waters. Chemosphere 79, 880-886.

Lapworth, D.J., Baran, N., Stuart, M.E., Manamsa, K., Talbot, J., 2015. Persistent and emerging microorganic contaminants in Chalk groundwater of England and France. Environ. Pollut. 203, 214-225.

Lapworth, D.J., Baran, N., Stuart, M.E., Ward, R.S., 2012. Emerging organic contaminants in groundwater: A review of sources, fate and occurrence. Environ. Pollut. 163, 287-303.

Launay, M.A., Dittmer, U., Steinmetz, H., 2016. Organic micropollutants discharged by combined sewer overflows - Characterisation of pollutant sources and stormwater-related processes. Water Research 104, 82-92. https://doi.org/10.1016/j.watres.2016.07.068

Lissalde, S., Charriau, A., Poulier, G., Mazzella, N., Buzier, R., Guibaud, G., 2016. Overview of the Chemcatcher ${ }^{\circledast}$ for the passive sampling of various pollutants in aquatic environments Part B: Field handling and environmental applications for the monitoring of pollutants and their biological effects. Talanta 148, 572-582. https://doi.org/10.1016/j.talanta.2015.06.076

Loos, R., Locoro, G., Comero, S., Contini, S., Schwesig, D., Werres, F., Balsaa, P., Gans, O., Weiss, S., Blaha, L., Bolchi, M., Gawlik, B.M., 2010. Pan-European survey on the occurrence of selected polar organic persistent pollutants in ground water. Water Res. 44, 4115-4126.

Lopez, B., Ollivier, P., Togola, A., Baran, N., Ghestem, J.-P., 2015. Screening of French groundwater for regulated and emerging contaminants. Sci. Total Environ. 518-519, 562-573.

Manamsa, K., Lapworth, D.J., Stuart, M.E., 2016. Temporal variability of micro-organic contaminants in lowland chalk catchments: New insights into contaminant sources and hydrological processes. Sci. Total Environ. 568, 566-577.

Marmonier, P., Maazouzi, C., Foulquier, A., Navel, S., François, C., Hervant, F., Mermillod-Blondin, F., Vieney, A., Barraud, S., Togola, A., Piscart, C., 2013. The use of crustaceans as sentinel organisms to evaluate groundwater ecological quality. Ecol. Eng. 57, 118-132.

Marques dos Santos, M., Hoppe-Jones, C., Snyder, S.A., 2019. DEET occurrence in wastewaters: Seasonal, spatial and diurnal variability - mismatches between consumption data and environmental detection. Environ. Int. 132, 105038.

Marsalek, J., Chocat, B., 2002. International Report: Stormwater management. Water Sci. Technol. 46, 1-17.

Mermillod-Blondin, F., Voisin, J., Marjolet, L., Marmonier, P., \& Cournoyer, B., 2019. Clay beads as artificial trapping matrices for monitoring bacterial distribution among urban stormwater infiltration systems and their connected aquifers. Environmental monitoring and assessment, 191(2), 58.

Mermillod-Blondin, F., Simon, L., Maazouzi, C., Foulquier, A., Delolme, C., Marmonier, P., 2015. Dynamics of dissolved organic carbon (DOC) through stormwater basins designed for groundwater recharge in urban area: Assessment of retention efficiency. Water Res. 81, 2737.

Miège, C., Mazzella, N., Allan, I., Dulio, V., Smedes, F., Tixier, C., Vermeirssen, E., Brant, J., O'Toole, S., Budzinski, H., Ghestem, J.-P., Staub, P.-F., Lardy-Fontan, S., Gonzalez, J.-L., Coquery, M., Vrana, B., 2015. Position paper on passive sampling techniques for the monitoring of 
contaminants in the aquatic environment - Achievements to date and perspectives. Trends Environ. Anal. Chem. 8, 20-26.

Mills, G.A., Gravell, A., Vrana, B., Harman, C., Budzinski, H., Mazzella, N., Ocelka, T., 2014. Measurement of environmental pollutants using passive sampling devices - an updated commentary on the current state of the art. Env. Sci Process. Impacts 16, 369-373.

Müller, A., Österlund, H., Marsalek, J., Viklander, M., 2020. The pollution conveyed by urban runoff: A review of sources. Sci. Total Environ. 709, 136125.

Nogaro, G., Mermillod-Blondin, F., Montuelle, B., Boisson, J.-C., Bedell, J.-P., Ohannessian, A., Volat, B., Gibert, J., 2007. Influence of a stormwater sediment deposit on microbial and biogeochemical processes in infiltration porous media. Sci. Total Environ. 377, 334-348.

Page, D., Dillon, P., Mueller, J., Bartkow, M., 2010. Quantification of herbicide removal in a constructed wetland using passive samplers and composite water quality monitoring. Chemosphere 81, 394-399. https://doi.org/10.1016/j.chemosphere.2010.07.002

Page, D., Miotliński, K., Gonzalez, D., Barry, K., Dillon, P., Gallen, C., 2014. Environmental monitoring of selected pesticides and organic chemicals in urban stormwater recycling systems using passive sampling techniques. J. Contam. Hydrol. 158, 65-77.

Paijens, C., Bressy, A., Frère, B., Moilleron, R., 2020. Biocide emissions from building materials during wet weather: identification of substances, mechanism of release and transfer to the aquatic environment. Environ Sci Pollut Res 27, 3768-3791. https://doi.org/10.1007/s11356-01906608-7

Petrie, B., Gravell, A., Mills, G.A., Youdan, J., Barden, R., Kasprzyk-Hordern, B., 2016. In Situ Calibration of a New Chemcatcher Configuration for the Determination of Polar Organic Micropollutants in Wastewater Effluent. Environ. Sci. Technol. 50, 9469-9478.

Pigneret, M., Mermillod-Blondin, F., Volatier, L., Romestaing, C., Maire, E., Adrien, J., Guillard, L., Roussel, D. \& Hervant, F., 2016. Urban pollution of sediments: impact on the physiology and burrowing activity of tubificid worms and consequences on biogeochemical processes. Sci. Total Environ. 568, 196-207.

Pinasseau, L., Wiest, L., Fildier, A., Volatier, L., Fones, G.R., Mills, G.A., Mermillod-Blondin, F., Vulliet, E., 2019. Use of passive sampling and high resolution mass spectrometry using a suspect screening approach to characterise emerging pollutants in contaminated groundwater and runoff. Sci. Total Environ. 672, 253-263.

Pinasseau, L., Wiest, L., Volatier, L., Fones, G.R., Mills, G.A., Mermillod-Blondin, F., Vulliet, E., 2020. Calibration and field application of an innovative passive sampler for monitoring groundwater quality. Talanta 208, 120307.

Pitt, R., Clark, S., Field, R., 1999. Groundwater contamination potential from stormwater infiltration practices. Urban Water 20.

Postigo, C., Barceló, D., 2015. Synthetic organic compounds and their transformation products in groundwater: Occurrence, fate and mitigation. Sci. Total Environ. 503-504, 32-47.

Reemtsma, T., Alder, L., Banasiak, U., 2013. Emerging pesticide metabolites in groundwater and surface water as determined by the application of a multimethod for 150 pesticide metabolites. Water Res. 47, 5535-5545.

Regnery, J., Lee, J., Drumheller, Z.W., Drewes, J.E., Illangasekare, T.H., Kitanidis, P.K., McCray, J.E., Smits, K.M., 2017. Trace organic chemical attenuation during managed aquifer recharge: Insights from a variably saturated 2D tank experiment. J. Hydrol. 548, 641-651.

Reh, R., Licha, T., Geyer, T., Nödler, K., Sauter, M., 2013. Occurrence and spatial distribution of organic micro-pollutants in a complex hydrogeological karst system during low flow and high flow periods, results of a two-year study. Sci. Total Environ. 443, 438-445.

Sébastian, C., Becouze-Lareure, C., Lipeme Kouyi, G., Barraud, S., 2015. Event-based quantification of emerging pollutant removal for an open stormwater retention basin - Loads, efficiency and importance of uncertainties. Water Res. 72, 239-250. 
Shaw, M., Mueller, J.F., 2009. Time Integrative Passive Sampling: How Well Do Chemcatchers Integrate Fluctuating Pollutant Concentrations? Environ. Sci. Technol. 43, 1443-1448.

Sidhu, J.P.S., Ahmed, W., Gernjak, W., Aryal, R., McCarthy, D., Palmer, A., Kolotelo, P., Toze, S., 2013. Sewage pollution in urban stormwater runoff as evident from the widespread presence of multiple microbial and chemical source tracking markers. Sci. Total Environ. 463-464, 488496.

Sorensen, J.P.R., Lapworth, D.J., Nkhuwa, D.C.W., Stuart, M.E., Gooddy, D.C., Bell, R.A., Chirwa, M., Kabika, J., Liemisa, M., Chibesa, M., Pedley, S., 2015. Emerging contaminants in urban groundwater sources in Africa. Water Res. 72, 51-63.

Spahr, S., Teixidó, M., Sedlak, D.L., Luthy, R.G., 2020. Hydrophilic trace organic contaminants in urban stormwater: occurrence, toxicological relevance, and the need to enhance green stormwater infrastructure. Environ. Sci. Water Res. Technol. 6, 15-44.

Stuart, M., Lapworth, D., Crane, E., Hart, A., 2012. Review of risk from potential emerging contaminants in UK groundwater. Sci. Total Environ. 416, 1-21.

Stuart, M.E., Lapworth, D.J., Thomas, J., Edwards, L., 2014. Fingerprinting groundwater pollution in catchments with contrasting contaminant sources using microorganic compounds. Sci. Total Environ. 468-469, 564-577.

Swartjes, F.A., Van der Aa, M., 2019. Measures to reduce pesticides leaching into groundwaterbased drinking water resources: An appeal to national and local governments, water boards and farmers. Sci. Total Environ. 134186.

Tedoldi, D., Chebbo, G., Pierlot, D., Kovacs, Y., Gromaire, M.-C., 2016. Impact of runoff infiltration on contaminant accumulation and transport in the soil/filter media of Sustainable Urban Drainage Systems: A literature review. Sci. Total Environ. 569-570, 904-926.

Valhondo, C., Martinez-Landa, L., Carrera, J., Ayora, C., Nödler, K., Licha, T., 2018. Evaluation of EOC removal processes during artificial recharge through a reactive barrier. Sci. Total Environ. 612, 985-994.

Vermeirssen, E.L.M., Dietschweiler, C., Escher, B.I., van der Voet, J., Hollender, J., 2013. Uptake and release kinetics of 22 polar organic chemicals in the Chemcatcher passive sampler. Anal. Bioanal. Chem. 405, 5225-5236.

Voisin, J., Cournoyer, B., Marjolet, L., Vienney, A., \& Mermillod-Blondin, F. 2020. Ecological assessment of groundwater ecosystems disturbed by recharge systems using organic matter quality, biofilm characteristics, and bacterial diversity. Environmental Science and Pollution Research, 27(3), 3295-3308.

Voisin, J., Cournoyer, B., Vienney, A., Mermillod-Blondin, F., 2018. Aquifer recharge with stormwater runoff in urban areas: Influence of vadose zone thickness on nutrient and bacterial transfers from the surface of infiltration basins to groundwater. Sci. Total Environ. 637-638, 14961507.

Vrana, B., Allan, I.J., Greenwood, R., Mills, G.A., Dominiak, E., Svensson, K., Knutsson, J., Morrison, G., 2005. Passive sampling techniques for monitoring pollutants in water. TrAC Trends Anal. Chem. 24, 845-868.

Vrana, B., Smedes, F., Prokeš, R., Loos, R., Mazzella, N., Miege, C., Budzinski, H., Vermeirssen, E., Ocelka, T., Gravell, A., Kaserzon, S., 2016. An interlaboratory study on passive sampling of emerging water pollutants. TrAC Trends in Analytical Chemistry 76, 153-165. https://doi.org/10.1016/j.trac.2015.10.013

Vulliet, E., Cren-Olivé, C., 2011. Screening of pharmaceuticals and hormones at the regional scale, in surface and groundwaters intended to human consumption. Environ. Pollut. 159, 29292934.

Vulliet, E., Tournier, M., Vauchez, A., Wiest, L., Baudot, R., Lafay, F., Kiss, A., Cren-Olivé, C., 2014. Survey regarding the occurrence of selected organic micropollutants in the groundwaters of overseas departments. Environ. Sci. Pollut. Res. 21, 7512-7521. 
Wang, L., Stuart, M.E., Lewis, M.A., Ward, R.S., Skirvin, D., Naden, P.S., Collins, A.L., Ascott, M.J., 2016. The changing trend in nitrate concentrations in major aquifers due to historical nitrate loading from agricultural land across England and Wales from 1925 to 2150. Sci. Total Environ. 542, 694-705.

Winiarski, T., Bedell, J.-P., Delolme, C., Perrodin, Y., 2006. The impact of stormwater on a soil profile in an infiltration basin. Hydrogeol. J. 14, 1244-1251.

Zgheib, S., Moilleron, R., Chebbo, G., 2012. Priority pollutants in urban stormwater: Part 1 - Case of separate storm sewers. Water Res. 46, 6683-6692. 